\title{
Analysis of atrioventricular junction, ventricular mass, and ventriculoarterial junction in 43 specimens with atrial isomerism
}

\author{
S MARIO DE TOMMASI, LUCIANO DALIENTO, SIEW YEN HO, \\ FERGUS J MACARTNEY, * ROBERT H ANDERSON*
}

From the Department of Paediatrics, Cardiothoracic Institute, Brompton Hospital, and Thoracic Unit, The Hospital for Sick Children, London

SUMMARY We have analysed the atrioventricular junction, ventricular mass, and ventriculoarterial junction in 43 hearts with isomeric atrial chambers. Of the hearts, 32 had atrial chambers of bilateral right morphology while 11 had atrial chambers with bilateral left atrial characteristics. Among the hearts with right atrial isomerism, there were 13 biventricular hearts, all with ambiguous atrioventricular connection. Eight had a common valve and five had two atrioventricular valves. In the other 19 hearts, the atrial chambers were connected to only one ventricular chamber, 18 having double inlet ventricle through a common valve and the other having absence of the left atrioventricular connection. In these univentricular hearts, all possible types of ventricular morphology were found. The ventriculoarterial junction among these hearts with right isomerism showed great variation.

In the hearts with left atrial isomerism, nine hearts had two ventricles and two were univentricular. The biventricular hearts all had ambiguous atrioventricular connection, six via a common valve and three via two valves. The two univentricular hearts both had double inlet via a common valve, one to a chamber of right ventricular type and the other to a chamber of left ventricular type. Both had rudimentary chambers of complementary pattern. The ventriculoarterial junction again showed much variation.

Statistical analysis showed that pulmonary obstruction and a univentricular heart were both significantly more frequent in association with right compared with left isomerism. Significant differences were also noted in the two groups in terms of ventriculoarterial connections and infundibular morphology.

Visceral heterotaxy is known to be a harbinger of complex congenital heart disease. ${ }^{1-6}$ Complex congenital heart disease in itself is a fertile ground for misunderstanding and incomprehension. When associated with visceral heterotaxy, the potential for confusion is greatly magnified. Until recently controversy in this area has been of mostly academic interest. Progress in cardiac surgery, however, means that repair of certain patients with isomeric atrial chambers and complex anomalies can now be achieved. ${ }^{7}$ As a prerequisite of successful surgery complete understanding and unequivocal description of anatomy are essential. The problems con-

\footnotetext{
* FJM and RHA are supported by the British Heart Foundation together with the Vandervell Foundation and the Joseph Levy Foundation, respectively.

Received for publication 10 July 1980
}

cerning atrial morphology itself, as well as venous drainage, in atrial isomerism have been discussed elsewhere recently ${ }^{8}{ }^{8}$ and have been analysed by us in a recent paper. ${ }^{10}$ The purpose of this paper is to consider problems of morphology and nosology at the atrioventricular junction, in the ventricular mass, and at the ventriculoarterial junction.

\section{Subjects and methods}

We examined 43 specimens known to exhibit atrial isomerism as judged on the basis of the morphology of the atrial appendages and their junction with the smooth walled atrium. ${ }^{810}$ Thirty-two specimens had two atrial chambers each with right atrial characteristics and 11 had atrial chambers with bilateral left characteristics. 
We have termed these groups right atrial isomerism and left atrial isomerism, respectively. The majority of patients had formed the basis of the study of atrial morphology and venous connections ${ }^{10}$ but some of these hearts had been processed for study of the conduction system ${ }^{11}$ and were therefore excluded and replaced by new material. Sequential analysis was conducted, employing the terms and definitions suggested by Tynan et al..$^{12}$

After analysis of the specimens, the results were analysed on the University of London Computer using the Statistical Package for the Social Sciences. We processed the morphological features identified so as to see which features were associated with one form of isomerism rather than the other.

Results: right atrial isomerism (Table 1)
Twelve of the 32 cases $(37.5 \%)$ had dextrocardia and $20(62.5 \%)$ laevocardia.

\section{ATRIOVENTRICULAR JUNCTION}

Of the 32 cases, the atria were connected to two chambers in the ventricular mass in 13 hearts (Fig. 1) and to only one ventricular chamber in 18 hearts (Fig. 2). In the remaining univentricular heart the left-sided atrial chamber had no connection with the ventricular mass (Fig. 3). The 13 biventricular hearts were considered to have an ambiguous atrioventricular connection. The mode of connection in these was via a common atrioventricular valve in eight cases and via two valves in five (Fig. 1). The left atrioventricular valve was cleft in one case and stenotic in another of those with two valves. The 19 univentricular hearts exhibited double inlet connections in 18, all via a common valve (Fig. 2, 4)

Table 1 Atrioventricular junction with right isomerism

\begin{tabular}{|c|c|c|c|c|c|c|c|c|c|c|c|}
\hline \multirow[t]{2}{*}{ Case no. } & \multicolumn{3}{|c|}{$A V$ connection } & \multicolumn{3}{|c|}{ Mode of conrection } & \multicolumn{2}{|c|}{ Vent mo } & \multicolumn{2}{|c|}{ Rud Chamb } & \multirow[t]{2}{*}{ Vent relation } \\
\hline & $A m b$ & $D I$ & Abs & Com & $2 v$ & $1 v$ & Biv & $U V H$ & Pres & $A b s$ & \\
\hline \multicolumn{12}{|c|}{ (a) With laevocardia } \\
\hline 1 & & $\therefore$ & & $\div$ & & & & Indet & &..+ & Nil \\
\hline 2 & & & & $\cdots$ & & & & RV & $\therefore$ & & Left inf \\
\hline 3 & & & & & & & & RV & & . & Nil \\
\hline 4 & & $\therefore$ & & & & & & LV & + & & Right ant \\
\hline 5 & & & & & 4 & & $\therefore$ & & & & Right ant \\
\hline 6 & & & & $\div$ & & & $\therefore$ & & & & Left post \\
\hline 7 & & t & & ++ & & & & LV & & & Right ant \\
\hline 8 & & - & & $\therefore$ & & & & RV & + & & Left inf \\
\hline 9 & & + & & $\therefore$ & & & & LV & $\because$ & & Right ant \\
\hline 10 & & & & & + & & + & & & & Left post \\
\hline 11 & + & & & $\therefore$ & & & + & & & & Right ant \\
\hline 12 & & + & & + & & & & $\mathbf{R V}$ & $\therefore$ & & Left inf \\
\hline 13 & &.+ & & $\therefore$ & & & & RV & $\therefore$ & & Left inf \\
\hline 14 & & & + & & & + & & RV & & + & Nil \\
\hline 15 & + & & & + & & & + & & & & Right ant \\
\hline 16 & & t & & $\cdots$ & & & & RV & + & & Right inf \\
\hline 17 & & & & $\therefore$ & & & $\therefore$ & & & & Right ant \\
\hline 18 & $\rightarrow$ & & & & + & & + & & & & Right ant \\
\hline 19 & $\div$ & & & $\therefore$ & & & $! \cdot$ & & & & Right ant \\
\hline 20 & + & & & & & & 4 & & & & Right ant \\
\hline \multicolumn{12}{|c|}{ (b) With dextrocardia } \\
\hline 21 & & + & & 4 & & & & Ind & & + & $\mathrm{Ni}^{1}$ \\
\hline 22 & & + & & $\because$ & & & & RV & + & & Left inf \\
\hline 23 & & + & & .. & & & & RV & + & & Left inf \\
\hline 24 & + & & & .. & & & + & & & & Left post \\
\hline 25 & + & & & + & & & + & & & & Right ant \\
\hline 26 & + & & & & 4 & & + & & & & Left ant \\
\hline 27 & & + & & $\therefore$ & & & & LV & $\div$ & & Left ant \\
\hline 28 & & + & & + & & & & RV & & + & \\
\hline 29 & & + & & -4 & & & & LV & + & & Left ant \\
\hline 30 & + & & & & + & & + & & & & Left sxs \\
\hline 31 & & + & & + & & & & RV & & 4. & Nil \\
\hline 32 & + & & & + & & & & RV & $\because$ & & Left inf \\
\hline
\end{tabular}

Abbreviations: AV, atrioventricular; Vent, ventricular; mo, morphology; Rud chamb, rudimentary chamber; Amb, ambiguous connection; DI, double inlet connection; Abs, absent connection; Com, common AV valve; $2 \mathrm{v}$, two AV valves; $1 \mathrm{v}$, one AV valve; Biv, biventricular heart; UVH, univentricular heart; Pres, present; Abs, absent; RV, right ventricular; LV, left ventricular; Indet, indeterminate; Nil, not applicable; ant, anterior; post, posterior; inf, inferior; sxs, side by side. Note that for relations the right ventricle is described relative to the left ventricle, but rudimentary chambers are described relative to main chambers irrespective of their morphology. 


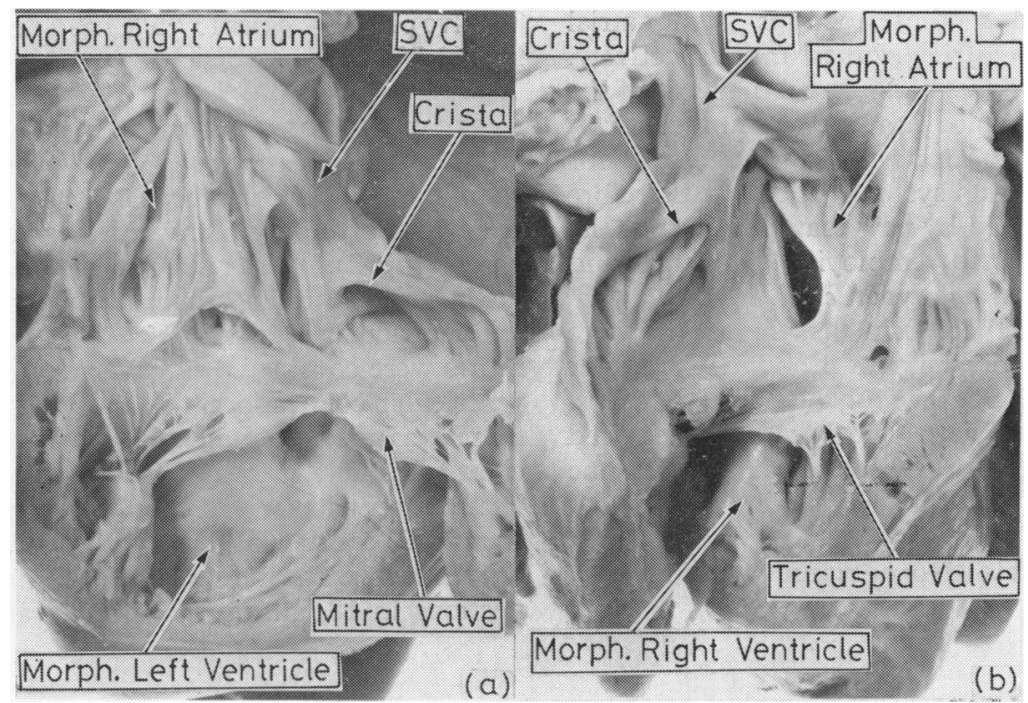

Fig. 1 Photographs of a heart with right atrial isomerism and ambiguous atrioventricular connection via two separate atrioventricular valves. The morphologically left ventricle is to the right of the morphologically right ventricle. Fig. 1 a shows the right-sided morphologically right atrium connecting to the right-sided morphologically left ventricle via a mitral valve. Fig. $1 b$ shows the left-sided morphologically right atrium connecting to the left-sided morphologically right ventricle via a tricuspid valve. Note the bilateral superior venae cavae (SVC) and the bilateral cristae. The atrial septum exhibits a patent foramen ovale.

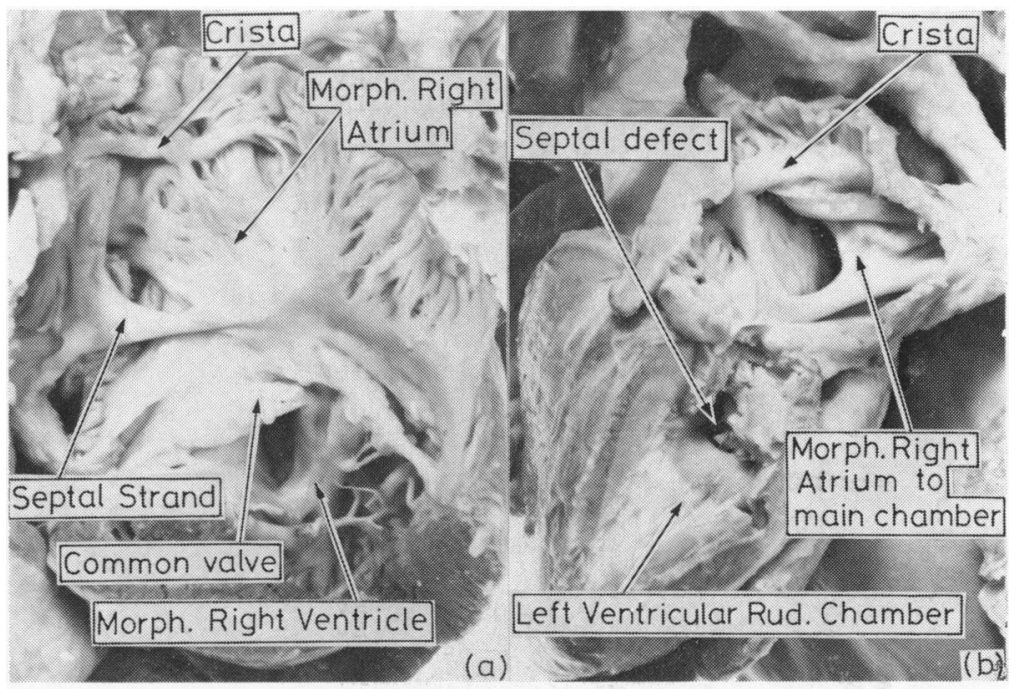

Fig. 2 Photographs of a heart with right atrial isomerism and double inlet ventricle via a common atrioventricular valve. The ventricular morphology is that of a univentricular heart of right ventricular type with left-sided rudimentary chamber. Fig. 2a shows the common valve draining both atria of right morphology exclusively to the morphologically right ventricular chamber. Fig $2 b$ shows the left-sided rudimentary chamber of left ventricular type which has no connection to the left-sided morphologically right atrial chamber. 
which minimally overrode the rudimentary chamber in three cases and had an accessory orifice in one case. As indicated above, the remaining univentricular heart had absence of the left atrioventricular connection, the right valve being totally committed to the ventricular chamber (Fig. 3). In the whole group, 26 cases $(81 \%$ ) had a common atrioventricular valve and only three cases $(9 \%$ ) had two normal atrioventricular valves.

\section{VENTRICULAR MASS}

As indicated above, 19 cases $(59 \%)$ were univen- tricular hearts and 13 cases $(41 \%)$ were biventricular. Ten of the 13 biventricular hearts had laevocardia. In the whole group of biventricular hearts the right ventricle was anterior and to the right of the left ventricle in eight cases (seven in laevocardia and one in dextrocardia); anterior and to the left in one case (dextrocardia); posterior and to the left in three cases (laevocardia); left and side by side in one case (dextrocardia). In the 19 univentricular hearts, all possible types of ventricular morphology were encountered (Fig. 5). Five cases had a main chamber of left ventricular type with rudimentary chambers

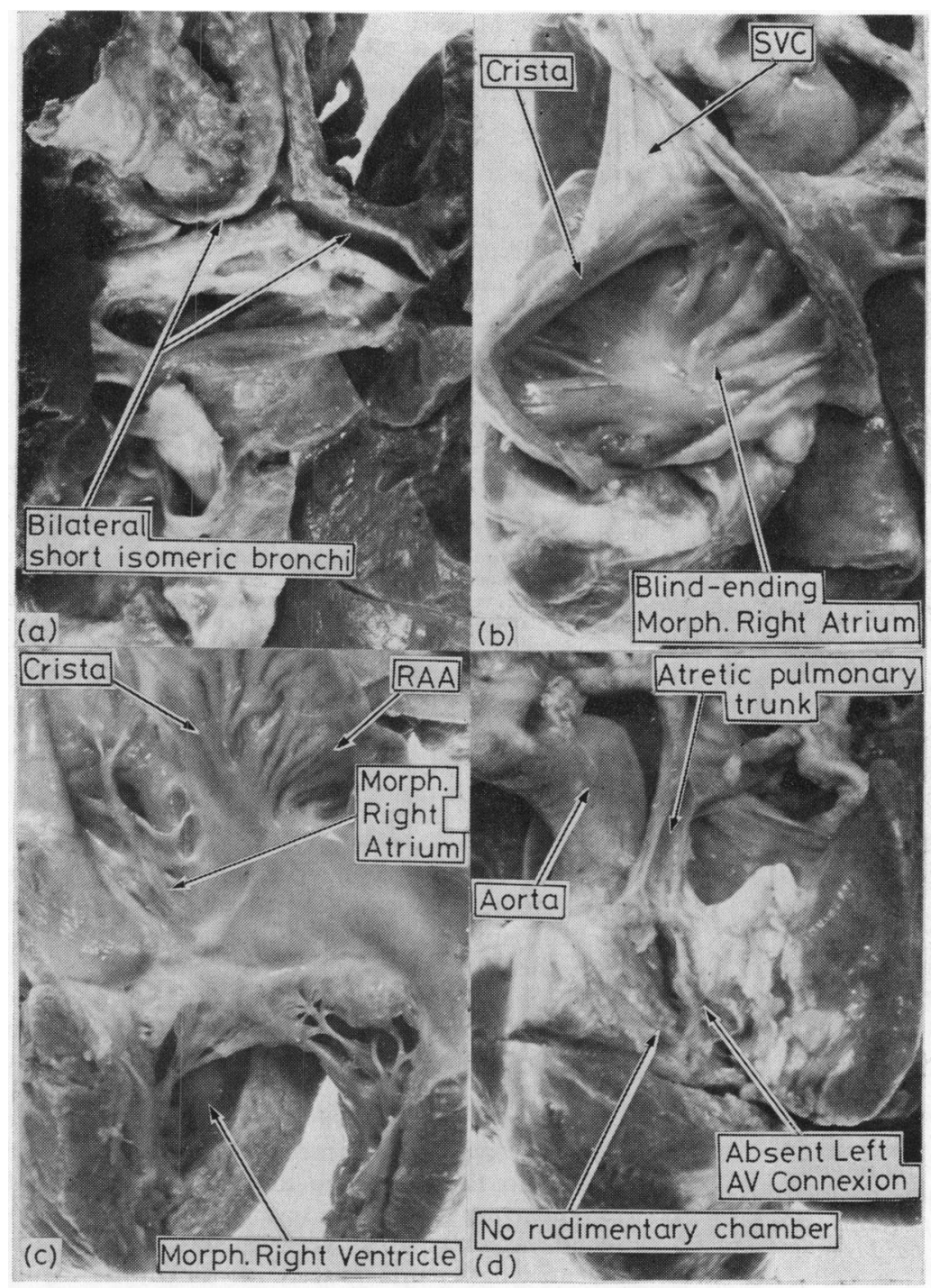

Fig. 3 Photographs of a heart with right atrial isomerism and absence of the left atrioventricular connection. The ventricular morphology is that of a univentricular heart of right ventricular type with no demonstrable rudimentary chamber. Fig $3 a$ shows the bilateral short isomeric bronchi. Fig. $3 b$ shows the blind-ending left-sided morphologically right atrium. Fig. 3c shows the right-sided morphologically right atrium connecting to the morphologically right ventricle. Fig. $3 d$ shows the atrioventricular sulcus which separates the left-sided atrium from the ventricular mass. Incisions in the ventricular wall beneath this sulcus failed to reveal the presence of a rudimentary left ventricular chamber. The ventriculoarterial connection was single outlet via the aorta with pulmonary atresia. 
of right ventricular type, the rudimentary chamber being to the left and anterior in two cases and to the right and anterior in the remainder. Twelve hearts had a main chamber of right ventricular type, eight with a left posterior rudimentary chamber of left ventricular type (Fig. 2), one with a right posterior rudimentary chamber of left ventricular type, and three having no demonstrable rudimentary chamber (Fig. 3). In the remaining two cases with a sole chamber in the ventricular mass, the trabecular pattern was considered indeterminate (Fig. 4).

\section{COMMUNICATIONS BETWEEN CHAMBERS IN} VENTRICULAR MASS

All biventricular hearts had ventricular septal de-

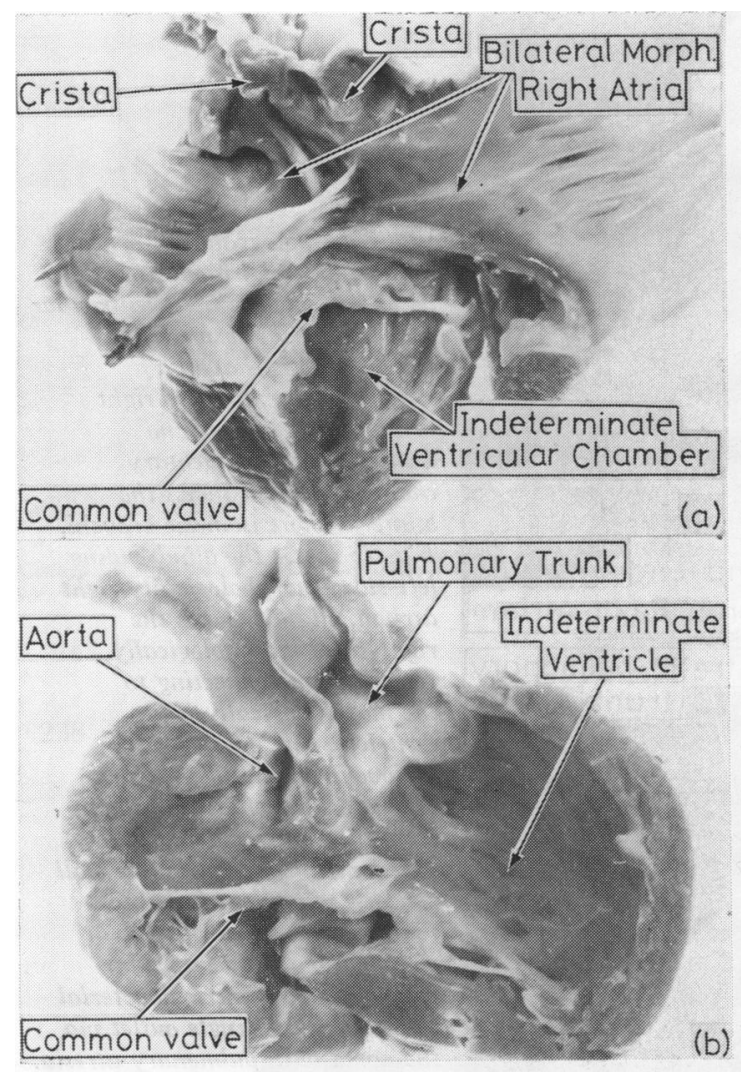

Fig. 4 Photographs of a heart with right atrial isomerism and double inlet ventricle via a common valve. The ventricular morphology is that of a univentricular heart of indeterminate type without rudimentary chamber. Fig. $4 a$ shows the opened atrioventricular junction. Fig. $4 b$ shows the ventriculoarterial connection of double outlet ventricle, the aorta being to the right of the pulmonary trunk. Note the bilateral infundibulum.
Table 2 Ventriculoarterial junction and associated anomalies with right isomerism

\begin{tabular}{|c|c|c|c|c|c|c|c|}
\hline $\begin{array}{l}\text { Case } \\
\text { no. }\end{array}$ & Conn & Relation & Infund & Arch & Coar & $P D A$ & Pulm ob \\
\hline \multicolumn{8}{|c|}{ (a) With laevocardia } \\
\hline 1 & DOUH & Right ant & Ao & $\mathbf{R}$ & & + & Atr \\
\hline 2 & DOUH & Right post & Bil & $\mathrm{L}$ & & & \\
\hline 3 & DOUH & Right post & Bil & $\bar{L}$ & + & + & \\
\hline 4 & Conc & Right ant & Pulm & $\mathbf{L}$ & & & St \\
\hline 5 & DORV & Right post & Bil & $\mathbf{R}$ & & & St \\
\hline 6 & Disc & Left ant & Bil & $\mathbf{R}$ & & + & \\
\hline 7 & Disc & Right ant & Ao & L & & + & \\
\hline 8 & SOUH & Post & Ao & $\overline{\mathbf{R}}$ & & + & Atr \\
\hline 9 & SOUH & Post & Ao & $\mathrm{L}$ & & & Atr \\
\hline 10 & Conc & Right post & Pulm & $\bar{L}$ & & & \\
\hline 11 & Disc & Right ant & Ao & $\mathbf{L}$ & & + & Atr \\
\hline 12 & SOUH & Post & Ao & L & & t. & Atr \\
\hline 13 & DOUH & Left ant & Bil & $\mathbf{R}$ & & + & Atr \\
\hline 14 & DOUH & Right ant & Ao & $\mathbf{L}$ & & + & Atr \\
\hline 15 & DORV & Left ant & Bil & $\bar{L}$ & + & + & \\
\hline 16 & DOUH & Right post & Bil & $\mathbf{L}$ & & + & \\
\hline 17 & Disc & Right ant & Ao & $\bar{L}$ & & + & Atr \\
\hline 18 & DORV & Right post & Bil & $\mathbf{L}$ & & & St \\
\hline 19 & Disc & Right ant & Ao & $\mathbf{R}$ & & & St \\
\hline 20 & DORV & Left ant & Bil & $\mathbf{R}$ & & + & Atr \\
\hline \multicolumn{8}{|c|}{ (b) With dextrocardia } \\
\hline 21 & DOUH & Left ant & $\mathrm{Bil}^{\star}$ & $\mathbf{L}$ & & & St \\
\hline 22 & DOUH & Right ant & Bil & $\mathbf{L}$ & & + & Atr \\
\hline 23 & DOUH & Right ant & Bil & $\bar{L}$ & & & St \\
\hline 24 & Disc & Left ant & Ao & $\mathbf{R}$ & & + & St \\
\hline 25 & DORV & Right ant & Bil & L & & & St \\
\hline 26 & DORV & Left post & Bil & $\overline{\mathbf{R}}$ & & & St \\
\hline 27 & Conc & Right post & Pulm & $\mathbf{R}$ & & + & \\
\hline 28 & DOUH & Right post & Ao & $\mathbf{R}$ & & + & Atr \\
\hline 29 & Disc & Left ant & Ao & $\mathbf{R}$ & & + & Atr \\
\hline 30 & Disc & Left ant & Ao & $\mathbf{R}$ & & & St \\
\hline 31 & SOUH & Right post & Pulm & L & $+\star \star$ & + & \\
\hline 32 & DOUH & Left ant & Ao & $\mathbf{R}$ & & + & Atr \\
\hline
\end{tabular}

Conn, ventriculoarterial connection; coar, coarctation; Infund, infundibular morphology; Arch, aortic arch; PDA, persistent ductus arteriosus; Pulm ob, pulmonary obstruction; DOUH, double outlet univentricular heart without rudimentary chamber; Conc, ventriculoarterial concordance; DORV, double outlet right ventricle; Disc, ventriculoarterial discordance; SOUH, single outlet univentricular heart without rudimentary chamber; ant, anterior; post, posterior; Pulm, subpulmonary infundibulum alone; Ao, subaortic infundibulum alone; Bil, bilateral infundibulum; $R$, right L, left; Atr, pulmonary atresia, St, stenosis.

* This case had arterial-atrioventricular valve discontinuity but aortic-pulmonary continuity.

$\star \star$ This case had aortic atresia.

fects, in all those with common atrioventricular valves the defects being as expected for a complete atrioventricular defect. In three cases with two valves the defect was of the perimembranous inlet type. ${ }^{13}$ One of the three had an additional muscular infundibular defect. In two other hearts with two valves the defect was of perimembranous trabecular variety..$^{13}$

In four of the five univentricular hearts of left ventricular type well-formed outlet foramina were present. In the remaining univentricular heart of left ventricular type and in seven of the nine univentricular hearts of right ventricular type in which univentricular chambers were identified, the cham- 
bers had no outlet and were small pouches without an obvious connection with the main chamber. In that congealed blood was present in some of the pouches, a connection must have been present but it was not obvious. In the other two hearts defects were identified within the trabecular septum. In the five cases without rudimentary chambers there were perforce no ventricular septal defects present.

\section{VENTRICULOARTERIAL JUNCTION (Table 2)}

\section{Ventriculoarterial connections}

Three cases only (9\%) had concordant connections, one from a biventricular heart with ambiguous atrioventricular connection and two from univentricular hearts of left ventricular type with double inlet. Eight cases had discordant arterial connections (three having pulmonary valve atresia). Of these, six were biventricular hearts and two were univentricular hearts of left ventricular type with double inlet. A further six cases (including one with pulmonary atresia) had double outlet from a right ventricle. Eleven more cases had double outlet from a univentricular heart: two from a sole chamber of indeterminate type and nine from a chamber of right ventricular type. Four of them had pulmonary atresia. The remaining cases had single outlet of the heart, three having pulmonary atresia and one aortic atresia. In these cases it was not possible to trace the atretic arterial trunk to any ventricular chamber.

\section{Arterial relations}

The aortic valve was disposed in various positions relative to the pulmonary valve as shown in Table 2 and in Fig. 6. In the whole group it tended to stay anterior.

\section{Infundibular morphology}

This also was variable as shown in Table 2.

\section{Pulmonary outflow obstruction}

Pulmonary atresia was found in 13 cases (41\%):

Left Ventricular Type ( 5 cases)

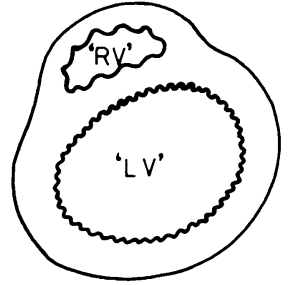

Left sided anterior rud. chamber ( 2 cases)

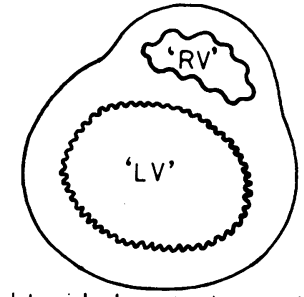

Right sided anterior rud. chamber ( 3 cases)

Right Ventricular Type (12 cases)

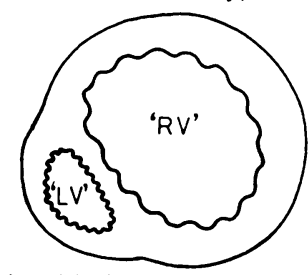

Left sided posterior $R C$ ( 8 cases)

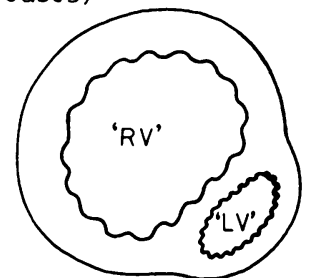

Right sided posterior RC (1 case)

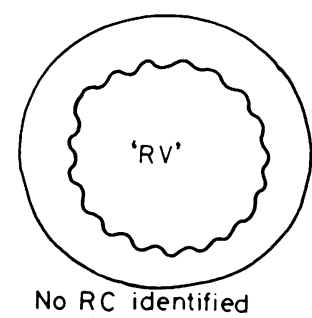

( 3 cases)
Fig. 5 Diagram illustrating the ventricular morphology encountered in the univentricular hearts studied with right atrial isomerism.

Indeterminate Type ( 2 cases)

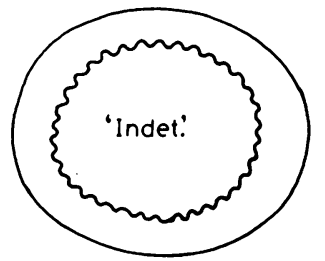


RIGHT ATRIAL ISOMERISM

LEFT ATRIAL ISOMERISM

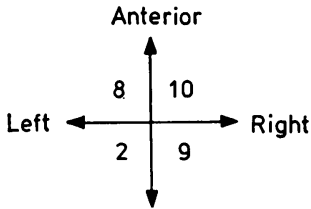

Posterior

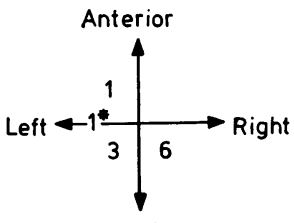

Posterior
Fig. 6 Diagram illustrating the variability in the aortic position relative to the pulmonary trunk in the hearts studied. One case had side-by-side arteries.

in eight cases it was valvular; in three cases the pulmonary trunk was also atretic. Pulmonary stenosis, valvular and/or infundibular, was found in 11 cases $(34 \%)$ : in six of them a bicuspid valve was observed. In the group as a whole, therefore, pulmonary outflow tract atresia or stenosis was found in 75 per cent of cases.

\section{Aortic outflow tract obstruction}

Aortic atresia was found in one case; subaortic stenosis in another case. Both of these had coarctation and/or isthmal hypoplasia, which was observed in a further two cases. In an additional case (univentricular heart of left ventricular type with outlet chamber of right ventricular type, and a discordant ventriculoarterial connection) obstruction to the aortic outflow tract was produced by a restrictive outlet foramen. In the whole group, therefore, aortic obstruction was as frequent as 16 per cent.
Aortic arch

This was on the left in 18 cases and on the right in 14. In the cases with laevocardia the arch was leftsided in 16 and right-sided in eight. In the cases with dextrocardia it was right-sided in six and left-sided in two.

\section{Persistent ductus arteriosus \\ This was present in 20 cases $(62 \cdot 5 \%)$.}

\section{Left atrial isomerism (Table 3 )}

\section{ATRIOVENTRICULAR JUNCTION}

The atria connected to two ventricular chambers (biventricular hearts with ambiguous connection) via a common valve in six (Fig. 7) and via two valves in three cases: in one of these cases the left atrioventricular valve was stenotic and in another one it was cleft. Only in one case were two normal atrioventricular valves observed. The remaining two hearts were univentricular, both with double inlet and a common atrioventricular valve: the valve minimally overrode the trabecular septum in one of these cases. In the whole group, eight cases (73\%) had a common atrioventricular valve.

\section{VENTRICULAR MASS}

In the nine biventricular hearts the right ventricle was on the right in eight cases (five in laevocardia and three in dextrocardia) and on the left in the other (dextrocardia-Fig. 7). The univentricular hearts were of right and left ventricular type, respectively. In the right ventricular type the rudimentary chamber was inferior and to the left, while in the left ventricular type it was anterior and to the left.

Table 3 Atrioventricular junction with left isomerism

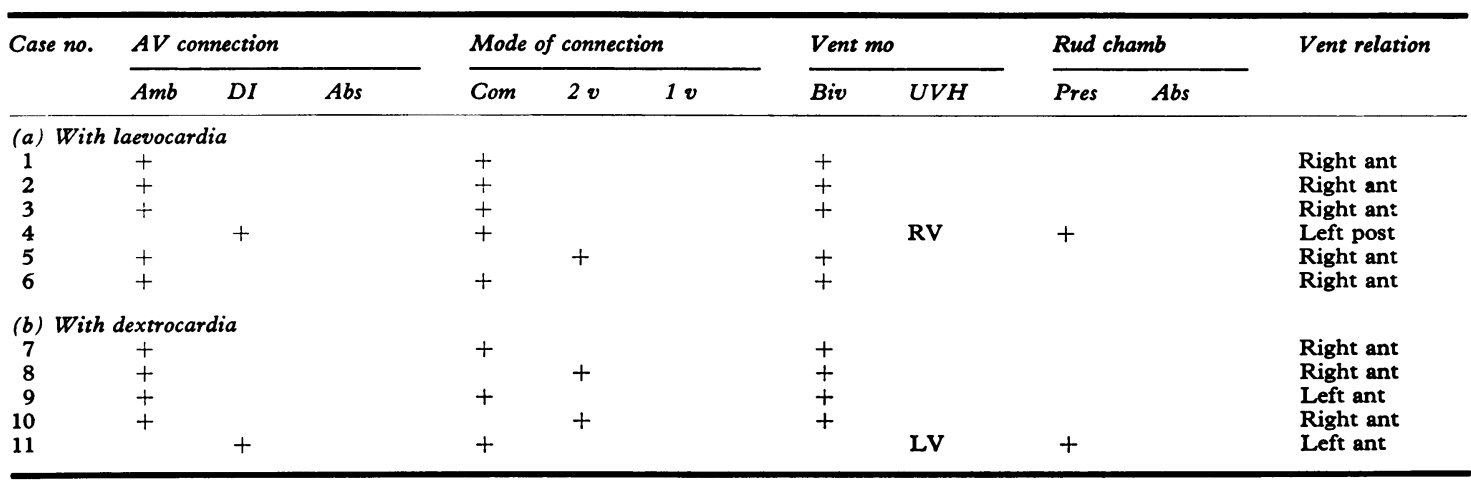

Abbreviations as for Table 1. 


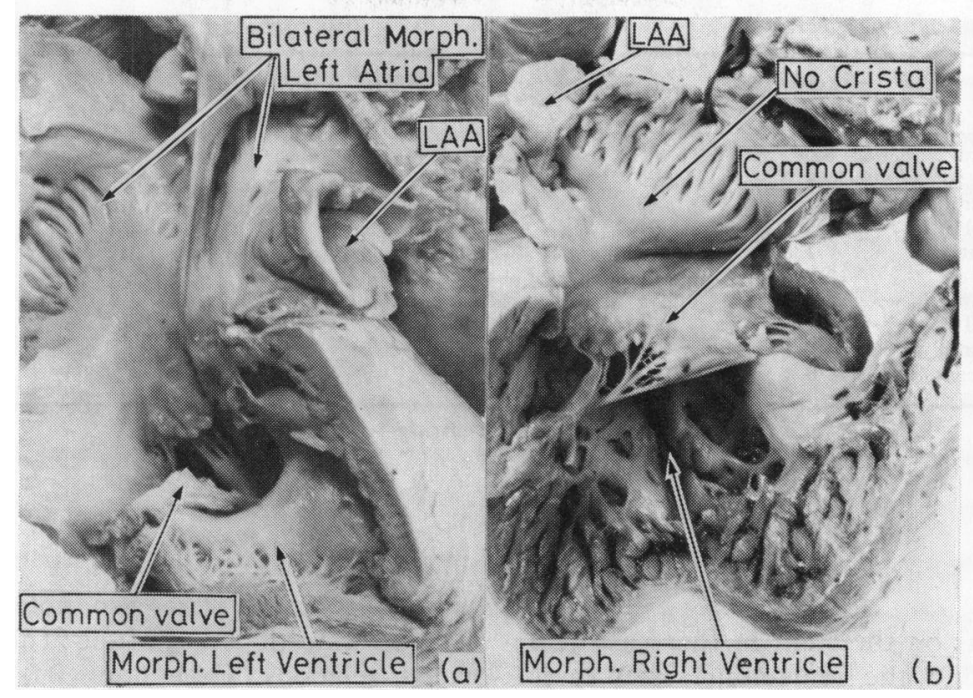

Fig. 7 Photographs of a heart with left atrial isomerism and ambiguous atrioventricular connection via a common atrioventricular valve. The morphologically left ventricle is to the right of the morphologically right ventricle.

Fig. $7 a$ shows the connection of the right-sided left atrium to the right-sided morphologically left ventricle.

Fig. $7 b$ shows the connection of the left-sided left atrium to the left-sided morphologically right ventricle. Note the bilateral absence of cristae and the bilateral left atrial appendages.

\section{COMMUNICATIONS BETWEEN CHAMBERS IN VENTRICULAR MASS}

Two biventricular hearts showed an intact ventricular septum. In the remaining biventricular heart with two valves a perimembranous trabecular defect ${ }^{13}$ was present. In the six biventricular hearts with common orifice a typical complete atrioventricular defect was present. In both the univentricular hearts outlet foramina were present.

\section{VENTRICULOARTERIAL JUNCTION (Table 4)}

\section{Ventriculoarterial connections}

The arterial connections were concordant in seven cases $(65 \%)$, including both univentricular hearts.

One biventricular heart had discordant connections with pulmonary valve atresia; the remaining three had double outlet right ventricle.

\section{Arterial relations}

The relations of arterial valves are shown in Table 2 and Fig. 6 . In the whole group the aorta tended to stay posterior.

\section{Infundibular morphology}

This is shown in Table 2.

Pulmonary outflow tract obstruction

Pulmonary atresia was found in only one case (9\%)。
Pulmonary stenosis was found in two cases (18\%), one being subvalvular and one being a stenotic bicuspid valve. In an additional case obstruction to pulmonary flow was caused by a restrictive outlet foramen. The overall incidence was 36 per cent.

\section{Aortic outflow tract obstruction}

Subaortic stenosis was observed in three cases $(27 \%)$ : one of them also had discrete coarctation and one had isthmal hypoplasia.

Table 4 Ventriculoarterial junction and associated malformations in left isomerism

\begin{tabular}{|c|c|c|c|c|c|c|c|c|}
\hline $\begin{array}{l}\text { Case } \\
\text { no. }\end{array}$ & Conn & Relation & Infund & Arch & Coar & $P D A$ & Pul ob & Ao ob \\
\hline $\begin{array}{l}\text { (a) } 1 \\
1 \\
2 \\
3 \\
4 \\
5 \\
6\end{array}$ & $\begin{array}{l}\text { With laev } \\
\text { DORV } \\
\text { Conc } \\
\text { Conc } \\
\text { Conc } \\
\text { Conc } \\
\text { DORV }\end{array}$ & $\begin{array}{l}\text { vocardia } \\
\text { Right post } \\
\text { Left post } \\
\text { Left post } \\
\text { Right post } \\
\text { Right post } \\
\text { Right post }\end{array}$ & $\begin{array}{l}\text { Bil } \\
\text { Pulm } \\
\text { Pulm } \\
\text { Pulm } \\
\text { Pulm } \\
\text { Bil }\end{array}$ & $\begin{array}{l}\text { L } \\
\text { L } \\
\text { L } \\
\text { L } \\
\text { L } \\
\text { L }\end{array}$ & $\begin{array}{l}+ \\
+\end{array}$ & $\begin{array}{l}+ \\
+ \\
+ \\
+\end{array}$ & St & $\begin{array}{l}+ \\
+ \\
+\end{array}$ \\
\hline $\begin{array}{l}\text { (b) } \\
7 \\
8 \\
9 \\
10 \\
11\end{array}$ & $\begin{array}{l}\text { With dextr } \\
\text { Conc } \\
\text { DORV } \\
\text { Disc } \\
\text { Conc } \\
\text { Conc }\end{array}$ & $\begin{array}{l}\text { trocardia } \\
\text { Right post } \\
\text { Left ant } \\
\text { Left sxs } \\
\text { Left post } \\
\text { Right post }\end{array}$ & $\begin{array}{l}\text { Pulm } \\
\text { Bil } \\
\text { Ao } \\
\text { Pulm } \\
\text { Pulm }\end{array}$ & $\begin{array}{l}\mathbf{R} \\
\mathbf{R} \\
\mathbf{R} \\
\mathbf{R} \\
\mathbf{L}\end{array}$ & & + & $\begin{array}{l}\text { St } \\
\text { Atr }\end{array}$ & \\
\hline
\end{tabular}

Abbreviations: As for Table 2 together with Ao ob, aortic obstruction; sxs, side by side. 
Table 5 Ventriculoarterial connections

\begin{tabular}{|c|c|c|c|c|c|c|c|}
\hline Type of isomerism & & Concordant & Discordant & $\begin{array}{l}\text { Double outlet } \\
\text { UVH }\end{array}$ & $\begin{array}{l}\text { Double outlet } \\
R V\end{array}$ & $\begin{array}{l}\text { Single outlet } \\
\text { heart }\end{array}$ & Row total \\
\hline Left & $\begin{array}{l}\text { Count } \\
\text { Row \% } \\
\text { Column \% } \\
\text { Total \% }\end{array}$ & $\begin{array}{c}4 \\
36 \cdot 4 \\
50 \cdot 0 \\
9 \cdot 3\end{array}$ & $\begin{array}{r}3 \\
27 \cdot 3 \\
27 \cdot 3 \\
7 \cdot 0\end{array}$ & $\begin{array}{l}0 \\
0 \\
0 \\
0\end{array}$ & $\begin{array}{c}4 \\
36 \cdot 4 \\
66 \cdot 7 \\
9 \cdot 3\end{array}$ & $\begin{array}{l}\mathbf{0} \\
\mathbf{0} \\
\mathbf{0} \\
0\end{array}$ & $\begin{array}{l}11 \\
25 \cdot 6\end{array}$ \\
\hline Right & $\begin{array}{l}\text { Count } \\
\text { Row \% } \\
\text { Column \% } \\
\text { Total \% } \\
\text { Column total } \\
\text { Per cent }\end{array}$ & $\begin{array}{c}4 \\
12 \cdot 5 \\
50 \cdot 0 \\
9 \cdot 3 \\
8 \\
18 \cdot 6\end{array}$ & $\begin{array}{l}8 \\
25 \cdot 0 \\
72 \cdot 7 \\
18 \cdot 6 \\
11 \\
25 \cdot 6\end{array}$ & $\begin{array}{c}14 \\
43 \cdot 8 \\
100 \cdot 0 \\
32 \cdot 6 \\
14 \\
32 \cdot 6\end{array}$ & $\begin{array}{c}2 \\
6 \cdot 3 \\
33 \cdot 3 \\
4 \cdot 7 \\
6 \\
14 \cdot 0\end{array}$ & $\begin{array}{c}4 \\
12 \cdot 5 \\
100 \cdot 0 \\
9 \cdot 3 \\
4 \\
9 \cdot 3\end{array}$ & $\begin{array}{c}32 \\
74 \cdot 4 \\
\\
43 \\
100 \cdot 0\end{array}$ \\
\hline
\end{tabular}

Raw $\chi^{2}=14 \cdot 02979$.

UVH, univentricular heart; RV, right ventricle

Four degrees of freedom.

Significance $=0.0072$.

\section{Aortic arch}

The aortic arch was on the right in four cases, all with dextrocardia. Of the remaining seven cases with left-sided arch, six had laevocardia and one dextrocardia.

\section{Persistent ductus arteriosus}

This was present in six cases (55\%).

\section{Statistical analysis of morphological features}

We analysed the frequency in left and right isomerism of the following morphological features: atrioventricular connection, mode of connection, ventricular morphology, ventricular relations, ventriculoarterial connections, arterial relations, infundibular morphology, aortic arch position, outflow tract obstruction, ductus arteriosus, cardiac position, and presence of a univentricular heart. There were significant differences in the association of pulmonary obstruction $(p=0.0243)$ and a univentricular heart $(p=0.0446)$ both of which were more common in right than left isomerism. Signi- ficant differences were also noted in ventriculoarterial connections as a whole (Table $5, \mathrm{p}=0.0072$ ), arterial relations (Table $6, p=0.0481$ ) and infundibular morphology (Table 7, p=0.0091), an anterior right-sided aorta, subaortic infundibulum, or bilateral infundibulum being much commoner in right isomerism. There was no significant difference in the association of the other features with the different types of atrial isomerism.

\section{Discussion}

Full comprehension of the type and frequency of cardiac anomalies associated with atrial isomerism is held back by lack of unanimity concerning the categorisation of such cases. It is surprising that, though the detailed anatomy of the atria in visceral heterotaxy was clearly described by Van Mierop and Wiglesworth, ${ }^{2}$ these workers at the same time pointing to the isomerism present, more recent investigators have continued to subdivide the cardiac features of these hearts into the groups of "asplenia" and "polysplenia". 6 Apart from the obvious deficiencies

Table 6 Arterial relations

\begin{tabular}{|c|c|c|c|c|c|c|}
\hline Type of isomerism & & $\begin{array}{l}\text { Aorta anterior } \\
\text { right }\end{array}$ & $\begin{array}{l}\text { Aorta anterior } \\
\text { left }\end{array}$ & $\begin{array}{l}\text { Aorta posterior } \\
\text { right }\end{array}$ & $\begin{array}{l}\text { Aorta posterior } \\
\text { left }\end{array}$ & Row total \\
\hline Left & $\begin{array}{l}\text { Count } \\
\text { Row \% } \\
\text { Column \% } \\
\text { Total \% }\end{array}$ & $\begin{array}{l}0 \\
0 \\
0 \\
0\end{array}$ & $\begin{array}{r}2 \\
18 \cdot 2 \\
200 \\
5 \cdot 0\end{array}$ & $\begin{array}{c}6 \\
54 \cdot 5 \\
40 \cdot 0 \\
15 \cdot 0\end{array}$ & $\begin{array}{c}3 \\
27 \cdot 3 \\
60 \cdot 0 \\
7 \cdot 5\end{array}$ & $\begin{array}{l}11 \\
27 \cdot 5\end{array}$ \\
\hline Right & $\begin{array}{l}\text { Count } \\
\text { Row \% } \\
\text { Column \% } \\
\text { Total \% } \\
\text { Column total } \\
\text { Per cent }\end{array}$ & $\begin{array}{l}10 \\
34 \cdot 5 \\
100 \cdot 0 \\
25 \cdot 0 \\
10 \\
25 \cdot 0\end{array}$ & $\begin{array}{l}8 \\
27 \cdot 6 \\
80 \cdot 0 \\
20 \cdot 0 \\
10 \\
25 \cdot 0\end{array}$ & $\begin{array}{l}9 \\
31 \cdot 0 \\
60 \cdot 0 \\
22 \cdot 5 \\
15 \\
37 \cdot 5\end{array}$ & $\begin{array}{c}2 \\
6 \cdot 9 \\
40 \cdot 0 \\
5 \cdot 0 \\
5 \\
12 \cdot 5\end{array}$ & $\begin{array}{l}29 \\
72 \cdot 5 \\
40 \\
100 \cdot 0\end{array}$ \\
\hline
\end{tabular}

Raw $\chi^{2}=7 \cdot 89969$.

Three degrees of freedom. Significance $=0.0481$.

Number of missing observations three. 
Table 7 Infundibular morphology

\begin{tabular}{|c|c|c|c|c|c|}
\hline $\begin{array}{l}\text { Type of } \\
\text { isomerism }\end{array}$ & & Subaortic & Subpulmonary & Bilaterul & $\begin{array}{l}\text { Row } \\
\text { total }\end{array}$ \\
\hline Left & $\begin{array}{l}\text { Count } \\
\text { Row \% } \\
\text { Column \% } \\
\text { Total \% }\end{array}$ & $\begin{array}{l}1 \\
9 \cdot 1 \\
6 \cdot 3 \\
2 \cdot 3\end{array}$ & $\begin{array}{c}6 \\
54 \cdot 5 \\
60 \cdot 0 \\
14 \cdot 0\end{array}$ & $\begin{array}{c}4 \\
36 \cdot 4 \\
23 \cdot 5 \\
9 \cdot 3\end{array}$ & $\begin{array}{l}11 \\
25 \cdot 6\end{array}$ \\
\hline Right & $\begin{array}{l}\text { Count } \\
\text { Row \% } \\
\text { Column \% } \\
\text { Total \% } \\
\text { Column total } \\
\text { Per cent }\end{array}$ & $\begin{array}{l}15 \\
46 \cdot 9 \\
93 \cdot 8 \\
34 \cdot 9 \\
16 \\
37 \cdot 2\end{array}$ & $\begin{array}{c}4 \\
12 \cdot 5 \\
40 \cdot 0 \\
9 \cdot 3 \\
10 \\
23 \cdot 3\end{array}$ & $\begin{array}{l}13 \\
40 \cdot 6 \\
76 \cdot 5 \\
30 \cdot 2 \\
17 \\
39 \cdot 5\end{array}$ & $\begin{array}{c}43 \\
100 \cdot 0\end{array}$ \\
\hline
\end{tabular}

Raw $\chi^{2}=9 \cdot 40113$.

Two degrees of freedom. Significance $=0.0091$.

of relating atrial morphology and situs to abnormalities of the spleen, Macartney et al. ${ }^{8}$ and Caruso and Becker ${ }^{9}$ have pointed to the frequent inaccuracies which result from this approach. As we have shown, the atrial anatomy in cases of visceral heterotaxy is neither ambiguus or indeterminate. ${ }^{910}$ It is isomeric, the two atrial chambers being unequivocally identifiable as either bilateral right or bilateral left atria on the basis of the morphology of the atrial appendages and their junction with the smooth walled part of the atria. These points have been discussed at length in a recent paper, ${ }^{10}$ and it is the conclusions drawn from that study which have provided the basis for the sequential analysis presently described.

We have previously indicated that the terms "concordance" and "discordance" are inappropriate to describe the atrioventricular connections in the presence of atrial isomerism, and our more recent observations endorse this. ${ }^{10}$ This does not mean, however, that the atrioventricular connections cannot be described in atrial isomerism. In situs solitus or situs inversus, two situations exist whereby the atria may connect to two chambers in the ventricular mass (concordant or discordant connections) or to only one chamber (double inlet connection or absence of one connection). Our present study shows that the same two possibilities exist with isomeric atria. The problem is that "concordant" or "discordant" are inappropriate terms to describe the anatomical atrioventricular connection in a biventricular heart with isomeric atrial chambers. Instead this "situation" comprises a discrete and separate connection, namely an ambiguous atrioventricular connection. This term therefore describes only those cases in which isomeric atrial chambers connect with separate ventricular chambers. Not all hearts with isomeric atria have an ambiguous atrioventricular connection. As we have shown, in either right or left isomerism both atria can connect to the same ventricle (double inlet connection) which may be of left ventricular, right ventricular, or indeterminate morphology. Rarely there may be absence of one atrioventricular connection. Absence of the left connection only was found in our material, in one case with right isomerism, but absence of either connection must be expected in either form of atrial isomerism. Thus, our study shows that the atrioventricular connection in the presence of isomeric atrial chambers may be ambiguous, double inlet ventricle, or absence of one atrioventricular connection.

Most frequently with either ambiguous or double inlet connection the mode of connection is via a common atrioventricular valve. But again, any mode of connection ${ }^{12}$ must be anticipated, and we encountered cases with two valves and cases with straddling valves. In the presence of an ambiguous atrioventricular connection it is particularly important to describe the relations of the chambers in the ventricular mass, since the same ambiguous connection can exist in two discrete forms, namely when the right-sided atrial chamber be it of right or left morphology, connects to the morphologically right ventricle, or alternatively when the right-sided atrial chamber connects to a morphologically left ventricular chamber. There are various ways of describing these relations. Previously it has been suggested that the terms "d-loop" and "l-loop" be used. ${ }^{14}$ But, because of recent modifications in the definition and usage of the "loop", 5 these terms as we used them are no longer strictly appropriate. An alternative would be to use the terms "normally related chambers" or "inverted chambers", but this does not cater for intermediate categories nor could it cope with criss-cross hearts ${ }^{15}$ in hearts with isomeric atria. Bharati and $\mathrm{Lev}^{16}$ have also recently focused on the need to describe relations together with connections and cardiac position, and have advocated a system based on the cardiac position. Our own preference is simply to describe the position of the morphologically left ventricular chamber relative to the right ventricular chamber in terms of right-left, anteroposterior or superoinferior positions, remembering that in "crisscross" hearts with atrial isomerism it would be necessary to describe separately the positions of inlet, trabecular, and outlet ventricular components.

The point to be made is that in complex congenital malformations, atrioventricular connections, internal ventricular morphology, and ventricular relations all warrant description, as indicated by Bharati and Lev, ${ }^{16}$ but demand separate description. The "loop" may have a place in discussing ventricular morphology, but only when that morphology has been unequivocally described. For example, in the presence of atrial isomerism it has been shown 
that the ventricular internal morphology determines the disposition of the atrioventricular conduction system, and that this disposition can be economically described in terms of "d-loop" and "l-loop"." None the less, nomenclature primarily should account for and describe the facts. Ideally it should be understood by all observers, which is possible when comprehensive concepts and universal terms are used. In this respect we believe that the terms right-left, anterior-superior, and posterior-inferior, together with inlet, trabecular (body), and outlet parts of the ventricle can hardly be misunderstood, and for this reason should be used to describe the anatomy. Once the anatomy is objectively described then the embryological implications can be drawn, which, though largely speculative, can provide further understanding of special aspects such as disposition of the conduction system." If a "shorthand" is required for the two basic patterns of ventricular morphology, then our preference is for the terms "right-rand pattern" and "left-hand pattern" as illustrated by Van Praagh et al. ${ }^{5}$

Similar difficulties in nomenclature arise in consideration of the ventriculoarterial junction. Are we justified in using the term "transposition" in the presence of ambiguous atrioventricular connection? Complete transposition can be defined as the combination of atrioventricular concordance and ventriculoarterial discordance. Since we have already shown that atrioventricular concordance and discordance are inappropriate in atrial isomerism, so are the terms complete and corrected transposition as thus defined. Others may object to the terms as defined and prefer to add physiological considerations in defining "transposition". This approach will te non-productive in most cases of atrial isomerism because of the disordered venous return. ${ }^{10}$ Yet others use the term "transposition" to define arterial relations, and, as we have shown, these are particularly varied in the hearts presently studied. Therefore, it seems preferable to eschew usage of "transposition" in atrial isomerism, instead describing connections, relations, and morphology at the atrioventricular and ventriculoarterial junctions.

When viewed as a whole, our investigation of necropsy material has confirmed that complex malformations are found more frequently with right atrial isomerism than with left isomerism. But it has also shown that cases with relatively favourable anatomy can be found in patients with right atrial isomerism whereas very complicated malformations can occur with left atrial isomerism. Thus, though atrial isomerism can now be non-invasively diagnosed with a high degree of accuracy and differen- tiated into the right and left isomeric forms, ${ }^{17-19}$ careful angiographic and echocardiographic investigation should never be excluded since our study has shown that surgically correctable cases can exist in both groups.

We are indebted to our colleagues who contributed to many of the basic concepts on which this study is founded, particularly Anton Becker, Elliot Shinebourne, Michael Tynan, and James Wilkinson.

\section{References}

1 Ivemark BI. Implications of agenesis of the spleen on the pathogenesis of cono-truncus anomalies in childhood. Acta Paediatr Scand 1955; 44, suppl 104: 1-110.

2 Van Mierop LHS, Wiglesworth FW. Isomerism of the cardiac atria in the asplenia syndrome. Lab Invest 1962 ; 11 : 1303-15.

3 Moller JH, Nakib A, Anderson RC, Edwards JE. Congenital cardiac disease associated with polysplenia: a developmental complex of bilateral "leftsidedness". Circulation 1967; 36: 789-99.

4 Rose, V, Izukawa T, Moës CAF. Syndromes of asplenia and polysplenia. A review of cardiac and non-cardiac malformations in 60 cases with special reference to diagnosis and prognosis. $\mathrm{Br}$ Heart $\mathrm{f}$ 1975; 37: 840-52.

5 Van Praagh R, Weinberg PH, Van Praagh S. Malposition of the heart. In: Moss AJ, Adams FH, Emmanouilides GC, eds. Heart disease in infants, children and adolescents. 2nd ed. Baltimore: Williams and Wilkins, 1977: 394-416.

6 Stanger P, Rudolph AM, Edwards JE. Cardiac malpositions: an overview based on study of 65 necropsy specimens. Circulation 1977; 56: 159-72.

7 Ando F, Shirotani H, Kawai J, et al. Successful total repair of complicated cardiac anomalies with asplenia syndrome. $\mathcal{F}$ Thorac Cardiovasc Surg 1976; 72: 33-8.

8 Macartney FJ, Partridge JB, Shinebourne EA, Tynan MJ, Anderson RH. Identification of atrial situs. In: Anderson RH, Shinebourne EA, eds. Paediatric cardiology 1977. Edinburgh \& London: Churchill Livingstone, 1978: 16-26.

9 Caruso G, Becker AE. How to determine atrial situs? Considerations initiated by 3 cases of absent spleen with a discordant anatomy between bronchi and atria. Br Heart f 1979; 41: 559-67.

10 Macartney FJ, Zuberbuhler JR, Anderson RH. Morphological considerations pertaining to recognition of atrial isomerism. Consequences for sequential chamber localisation. Br Heart f 1980; 44: 657-67.

11 Dickinson DF, Wilkinson JL, Anderson KR, Smith A, Ho SY, Anderson RH. The cardiac conduction system in situs ambiguus. Circulation 1979; 59: 879-85.

12 Tynan MJ, Becker AE, Macartney FJ, QueroJiménez $M$, Shinebourne EA, Anderson RH. Nomenclature and classification of congenital heart disease. Br Heart $\mathcal{F}$ 1979; 41 : 544-53. 
13 Soto B, Becker AE, Moulaert AJ, Lie JI, Anderson RH. Classification of ventricular septal defects. $\mathrm{Br}$ Heart $\mathcal{f} 1980$; 43: 332-43.

14 Shinebourne EA, Macartney FJ, Anderson RH. Sequential chamber localization: logical approach to diagnosis in congenital heart disease. $\mathrm{Br}$ Heart $\mathfrak{f}$ 1976; 38: 327-40.

15 Anderson RH, Shinebourne EA, Gerlis LM. Crisscross atrioventricular relationships producing paradoxical atrioventricular concordance or discordance: their significance to nomenclature of congenital heart disease. Circulation 1974; 50: 176-80.

16 Bharati S, Lev M. Positional variations of the heart and its component chambers (Editorial). Circulation 1979; 59: 886-7.

17 Van Mierop LHS, Eisen S, Schiebler GL. The radio- graphic appearance of the tracheobronchial tree as an indicator of visceral situs. Am $\mathcal{F}$ Cardiol 1970; 26: 432-5.

18 Partridge JB, Scott O, Deverall PB, Macartney FJ. Visualization and measurement of the main bronchi by tomography as an objective indicator of thoracic situs in congenital heart disease. Circulation 1975; 51 : 188-96.

19 Soto B, Pacifico AD, Souza AS Jr, Bargeron MR Jr, Ermocilla R, Tonkin IL. Identification of thoracic isomerism from the plain chest radiograph. $A \mathcal{F} R$ 1978; 131: 995-1002.

Requests for reprints to Professor R H Anderson, Department of Paediatrics, Cardiothoracic Institute, Fulham Road, London SW3 6HP. 